\title{
I Kept the Part about Turning Fifty
}

"More on the theme of suddenly finding yourself at middle age and less perhaps about memories that are more telling to the writer than the reader."

-Rejection slip

So I lost the part about walking to school, the new subdivision after the war, unfinished, cutting through Kocha's field with all the dandelions (or a calf-high puddle of slush we waded in March), passing Ma Whiting's house, the beer bottles, cigarette cartons piled even above the trash can rim, still life-ing into the street, the dead end where she lived with her seven kids and no husband, how they ate jelly sandwiches. It was all they could afford, our parents said. The piss and stale dirt smell of her kids on the playground. One seemed to be named "Poopy." You could hear everyone, even his mother, call that out after school from the holey screen door, cigarette wrangling, misshapen housedress, the house with gray-green asphalt siding, the house that must have been there when Kocha's was still a farm and our yards planted in corn or beans.

"Poopy," she called, "Poopy, get in here."

Her voice gruff as old stone smashed along their unpaved driveway.

I decided to cut the scene where Miss Campbell, first grade, huffs and pulls a Whiting girl by her stained smock to the sink like the one in back of every room. She bends the girl under the faucet, lathers a hand soap to froth and washes the dirty girl's hair, fingers ram straight, but hands moving gently, effective 
through the tangle that surely becomes dark blond.

The suds cascade to the beige countertop,

down the face of the pine cabinet

where the art supplies were kept and, I remember, onto the checkerboard tile of the cold floor. 